\title{
Influence of binder systems on sintering characteristics, microstructures, and mechanical properties of PcBN composites fabricated by SPS
}

\author{
Shuna CHEN ${ }^{a, b}$, Hengzhong $\mathrm{FAN}^{a}$, Yunfeng $\mathrm{SU}^{a,{ }^{*}}$, Wensheng $\mathrm{LI}^{c}$, Jicheng $\mathrm{LI}^{a, b}$, \\ Bing YAN ${ }^{c}$, Junjie $\mathrm{SONG}^{a}$, Litian $\mathrm{HU}^{a}$, Yongsheng $\mathrm{ZHANG}^{a, *}$ \\ ${ }^{a}$ State Key Laboratory of Solid Lubrication, Lanzhou Institute of Chemical Physics, \\ Chinese Academy of Sciences, Lanzhou 730000, China \\ ${ }^{b}$ Center of Materials Science and Optoelectronics Engineering, University of Chinese Academy \\ of Sciences, Beijing 100049, China \\ ${ }^{c}$ School of Materials Science and Engineering, Lanzhou University of Technology, \\ Lanzhou 730050, China
}

Received: May 28, 2021; Revised: August 25, 2021; Accepted: September 11, 2021

(C) The Author(s) 2021.

\begin{abstract}
Cubic boron nitride (cBN) with high hardness, thermal conductivity, wear resistance, and chemical inertness has become the most promising abrasive and machining material. Due to the difficulty of fabricating pure cBN body, generally, some binders are incorporated among cBN particles to prepare polycrystalline cubic boron nitride (PcBN). Hence, the binders play a critical factor to the performances of PcBN composites. In this study, the PcBN composites with three binder systems containing ceramic and metal phases were fabricated by spark plasma sintering (SPS) from 1400 to $1700{ }^{\circ} \mathrm{C}$. The sintering behaviors and mechanical properties of the composites were investigated. Results show that the effect of binder formulas on mechanical properties mainly related to the compactness, mechanical performances, and thermal expansion coefficient of binder phases, which affect the carrying capacity of the composites and the bonding strength between binder phases and cBN particles. The PcBN composite with SiAlON phase as binder presented optimal flexural strength $(465 \pm 29 \mathrm{MPa})$ and fracture toughness $\left(5.62 \pm 0.37 \mathrm{MPa} \cdot \mathrm{m}^{1 / 2}\right)$, attributing to the synergistic effect similar to transgranular and intergranular fractures. Meanwhile, the excellent mechanical properties can be maintained a comparable level when the temperature even rises to $800{ }^{\circ} \mathrm{C}$. Due to the weak bonding strength and high porosity, the $\mathrm{PcBN}$ composites with $\mathrm{Al}_{2} \mathrm{O}_{3}-\mathrm{ZrO}_{2}(3 \mathrm{Y})$ and $\mathrm{Al}-\mathrm{Ti}$ binder systems exhibited inferior mechanical properties. The possible mechanisms to explain these results were also analyzed.
\end{abstract}

Keywords: polycrystalline cubic boron nitride $(\mathrm{PcBN})$; binder system; sintering characteristic; high temperature mechanical property; fracture mechanism

\footnotetext{
* Corresponding authors.

E-mail: Y. Su, yfsu@licp.cas.cn;

Y. Zhang, zhysh@licp.cas.cn
} 


\section{Introduction}

Cubic boron nitride $(\mathrm{cBN})$ possesses high thermal conductivity, wear resistance, chemical inertness, and excellent mechanical properties and is the second hardest material next to diamond [1,2]. It has become the most promising cutting component in the abrasive and machine tool industry because of its low chemical reactivity with iron $(\mathrm{Fe})$, nickel $(\mathrm{Ni})$, and related alloys; thereby it can compensate the defect of diamond reacting and decomposing at high temperatures [3-5].

Nevertheless, due to the high-strength covalent bonds and low self-diffusion coefficient of $\mathrm{B}$ and $\mathrm{N}$, it is difficult to obtain big single crystal of $\mathrm{cBN}$ (or pure cBN body) even under the extreme sintering condition of ultra-high temperature $\left(2000{ }^{\circ} \mathrm{C}\right)$ and pressure ( $\sim 7 \mathrm{GPa})[6,7]$. Similar to polycrystalline diamond, therefore, polycrystalline cubic boron nitride (PcBN) was proposed by combining $\mathrm{cBN}$ particles and appropriate amount of binder to fabricate the composites under relatively low temperatures and pressures [8]. Moreover, PcBN composites as cutting tools allow for efficient dry and finish machining for turning case hardened steels, ball bearing steel, and chilled cast iron in multiple operations like high/low cutting speeds, high/low feed rates, and continuous/intermittent cutting manner, which could obtain considerable economic benefits on account of reducing production costs $[4,9]$.

In PcBN composites, cBN particles mainly contribute to the high hardness and wear resistance for the monolithic materials. And more mechanical properties, such as strength, toughness, and service reliability, are depended on the binder systems and formulas. Hence, the binders play the vital roles in both synthesis processes of PcBN composites and their service properties [10]. Composition of appropriate system and amount of binder not only can reduce the sintering temperature and pressure, but also improve the properties of the sintered body [8]. According to the different application fields (hardened steel, cast iron, and other workpiece materials) and processing methods, proportioning schemes of PcBN composites with different characteristics were designed due to the factors of cBN content, particle size, and binder type [10-13]. Conventionally, some ceramic phases like $\mathrm{Al}_{2} \mathrm{O}_{3}$ [4,14], SiAlON [15], $\mathrm{Y}_{2} \mathrm{O}_{3}$ stabilized $\mathrm{ZrO}_{2}$ (YSZ) [16,17], MAX [13] phases with fine sinterability, and good carrying capacity, metallic phases like Al with low melting point, Ti with high reactivity, and $\mathrm{W}$ with similar thermal expansion coefficient [8], were usually chosen as binders. Ji et al. [5] reported a eutectic melt of $\mathrm{Y}-\mathrm{Si}-\mathrm{Al}-\mathrm{O}-\mathrm{N}$ system formed from $\mathrm{Y}_{2} \mathrm{O}_{3}, \mathrm{Al}_{2} \mathrm{O}_{3}, \mathrm{Si}_{3} \mathrm{~N}_{4}$, and $\mathrm{Al}$, which could accelerate the densification of the composites, improve mechanical properties and thermal performance. PcBN composites were reactively sintered by spark plasma sintering (SPS) through adding $14.7 \mathrm{wt} \% \quad \mathrm{Al}$ and $43 \mathrm{wt} \% \mathrm{Ti}$ as binder system. During sintering processes, the generation of new phases deriving from chemical reactions promoted chemical bonding with $\mathrm{cBN}$, whose relative density, bending strength, and fracture toughness reached $98.9 \% \pm 0.10 \%, 390.7 \pm 4.5 \mathrm{MPa}$, and $7.6 \pm 0.10 \mathrm{MPa} \cdot \mathrm{m}^{1 / 2}$, respectively [18]. In addition, considering the problem of phase transformation from cBN to hBN due to its metastability during hightemperature and long-time sintering, it is crucial to choose suitable sintering technology and process parameters. SPS, a superior sintering technology to heat powder materials via a sequence of direct current pulses [19], possesses high heating rate, and short holding time [20], which can shorten the exposure time of the $\mathrm{cBN}$ grains at high temperatures and suppress phase transformation from $\mathrm{cBN}$ to $\mathrm{hBN}[18,21]$.

Moreover, due to the heat generated by serious friction, high speed or high feed rate would result in local high temperature of PcBN composites during dry machining processing $[22,23]$. It was reported that the average cutting temperatures of the tool-chip were ranged from 400 to $800{ }^{\circ} \mathrm{C}$ when machining at feed rate of $0.25 \mathrm{~mm} / \mathrm{rev}$ and cutting speed from 35$125 \mathrm{~m} / \mathrm{min}$ by PcBN composite tools [22]. With the temperature rising during processing, the mechanical performance and wear resistance of PcBN composites were frequently degraded, thereby bringing down the tool life $[24,25]$. However, few relative researches on evolution of mechanical properties with the increment of temperature could be found. Thus, it is of great significance of investigating the high temperature mechanical properties of PcBN composite to master its performances at actual service status and material design.

In present work, three systems of binders consisting of ceramic and metal phases were selected to fabricate PcBN composites by SPS. The sintering characteristics and phase transition behaviors, together with the compositions, microstructure, and mechanical properties of each proportioning scheme at different sintering temperatures were investigated. Moreover, aiming at high temperature service conditions, the mechanical 
properties at elevated temperatures up to $800{ }^{\circ} \mathrm{C}$ were investigated based on the optimal proportioning scheme, followed by discussing the fracture behaviors of the composites.

\section{Materials and methods}

Commercially available cBN particles $(5-10 \mu \mathrm{m}$; Zhengzhou Zhongnan Jete Superabasives Co., Ltd., Zhengzhou, China) was chosen as raw material. Al and Ti powder ( $75 \mu \mathrm{m}$; Beijing Huisheng Advanced Materials Technology Co., Ltd., Beijing, China), $\mathrm{Si}_{3} \mathrm{~N}_{4}$ powder ( $20 \mathrm{~nm}$, purity 99.9\%; Beijing Huawei Ruike Chemical Co., Ltd., Beijing, China), AlN powder ( $\sim 40 \mathrm{~nm}$, purity 99.9\%; Beijing Huawei Ruike Chemical Co., Ltd., Beijing, China), $\alpha-\mathrm{Al}_{2} \mathrm{O}_{3}$ powder (80-100 nm, purity 99.9\%; Jiangsu Lida High-Tech Special Materials Co., Ltd., Jiangsu, China), $\mathrm{Y}_{2} \mathrm{O}_{3}$ powder ( $\sim 50 \mathrm{~nm}$, purity 99.9\%; Beijing Huawei Ruike Chemical Co., Ltd., Beijing, China), and $\mathrm{ZrO}_{2}(3 \mathrm{Y})$ powder (10-20 nm, purity 99.9\%; Jiangsu Lida High-Tech Special Materials Co., Ltd., Jiangsu, China) were applied in binder systems. The proportioning schemes of PcBN composites were designed with three different binder systems and formulas. The corresponding samples were marked as Samples S1, S2, and S3. Detail components and the proportions are listed in Table 1 . The relevant raw powders were mixed by ball milling in ethanol solution for $20 \mathrm{~h}$ and then dried at $70{ }^{\circ} \mathrm{C}$ for $24 \mathrm{~h}$. The homogeneous mixtures were dry-pressed in a steel mold for $10 \mathrm{~min}$ at a pressure of $300 \mathrm{MPa}$ to obtain consolidated green body. Subsequently, the green body was equipped in a graphite die and sintered by SPS. Sintering temperature was measured by an infrared thermometer through graphite pressing rod with a penetrating hole and graphite block close to sample, to more accurately master the actual temperature of the sample. A graphite paper with thickness of $0.2 \mathrm{~mm}$ was inserted between the graphite block and graphite die to ensure fully contact to pass the uniformly current. The sintered procedures were conducted at different temperatures for $10 \mathrm{~min}$ in vacuum with the

Table 1 Component mass ratios (wt\%) of three composites

\begin{tabular}{ccccccccc}
\hline Sample & $\mathrm{cBN}$ & $\mathrm{Si}_{3} \mathrm{~N}_{4}$ & $\mathrm{AlN}$ & $\mathrm{Y}_{2} \mathrm{O}_{3}$ & $\mathrm{Al}_{2} \mathrm{O}_{3}$ & $\mathrm{ZrO}_{2}(3 \mathrm{Y})$ & $\mathrm{Al}$ & $\mathrm{Ti}$ \\
\hline $\mathrm{S} 1$ & 50 & 22 & 14 & 4 & 10 & - & - & - \\
$\mathrm{S} 2$ & 50 & - & - & - & 45 & 5 & - & - \\
$\mathrm{S} 3$ & 45 & - & - & - & - & - & 15 & 40 \\
\hline
\end{tabular}

heating rate of about $125^{\circ} \mathrm{C} / \mathrm{min}$. A bidirectional pressure of $35 \mathrm{MPa}$ was adopted in the axial direction of the graphite mold.

Density measurements of the composites were carried out using the Archimedes principle according to the standard ISO 18754:2003. The apparent porosity $\left(\pi_{\mathrm{a}}\right)$ and bulk density $\left(\rho_{\mathrm{b}}\right)$ were calculated from Eqs. (1) and (2):

$$
\begin{aligned}
& \pi_{\mathrm{a}}=\left(m_{3}-m_{1}\right) /\left(m_{3}-m_{2}\right) \times 100 \\
& \rho_{\mathrm{b}}=m_{1} /\left(m_{3}-m_{2}\right) \times \rho_{1}
\end{aligned}
$$

where $m_{1}, m_{2}$, and $m_{3}$ are the dry weight, buoyant weight, and wet weight of the samples, respectively. $\rho_{1}$ is the density of immersed liquid at experimental temperature.

The Vickers hardness (HV) of specimens was determined by indentation test using a microhardness tester (MH-5-VM) on the polished surface of specimens under $500 \mathrm{~g}$ and keeping for $5 \mathrm{~s}$. The specimens were machined into $3 \mathrm{~mm} \times 4 \mathrm{~mm} \times 25 \mathrm{~mm}$ and $2 \mathrm{~mm} \times 4 \mathrm{~mm} \times$ $25 \mathrm{~mm}$ for the flexural strength and fracture toughness tests, respectively. The tests were conducted on an electric universal testing machine (AGS-X-20KN) at room temperature (RT) and high temperatures (400, 600 , and $800{ }^{\circ} \mathrm{C}$ ). Single-edge notched beam (SENB) tests were conducted to measure the fracture toughness with a span of $16 \mathrm{~mm}$ and a crosshead speed of $0.05 \mathrm{~mm} / \mathrm{min}$. The flexural strengths were measured using a 3-point flexural test method with a span of $20 \mathrm{~mm}$ and a crosshead rate of $0.5 \mathrm{~mm} / \mathrm{min}$. Noted that the values presented are the average values of 5-8 repeats. When testing the high temperature mechanical properties, the operating equipments were placed in a furnace to create a high temperature environment, as shown in Fig. 1. At the beginning of the test, the temperature rose to target value and hold for $5 \mathrm{~min}$ to ensure specimen reach the corresponding temperature.

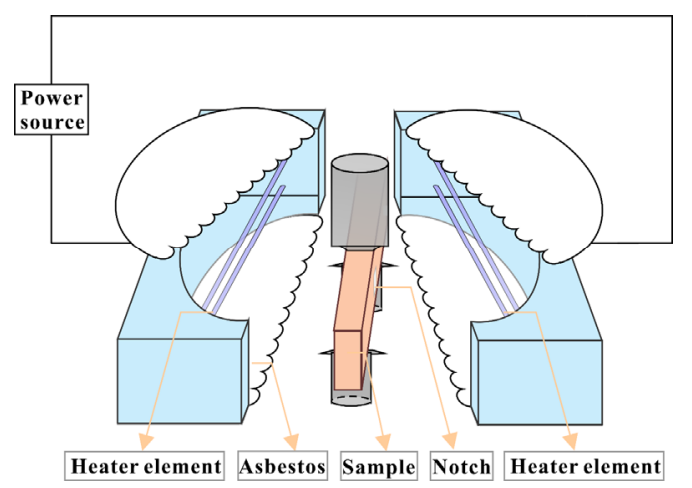

Fig. 1 Schematic diagram of high temperature operating equipment of mechanical test. 
The microstructures, morphologies of polished and fracture surfaces of the samples, as well as crack propagation patterns were characterized by the scanning electron microscope (JSM-5600LV, Japan), high resolution field emission scanning electron microscope (SU8020, Hitachi, Japan and Quanta 650 FEG, FEI, USA) equipped with backscattered electron (BSE) images, and energy dispersive spectrum analysis (EDS). The crystalline phases were identified qualitatively using X-ray diffraction (XRD) spectrum analysis (EMPYREAN, PANalytical, the Netherlands).

\section{Results and discussion}

\section{1 Phase composition, microstructure, and density of the PCBN composites}

Various systems of binders have complicate influence on the compositions of PcBN composites, and typically there are new phases generated from chemical reaction during sintering. The composites sintered at different temperatures were analyzed by XRD, and the results are shown in Fig. 2. It can be observed that several relevant new phases were detected in Samples S1 and $\mathrm{S} 3$, indicating chemical reaction existed during the sintering process in their composition systems. In contrast, the spectra of Sample S2 show the phases of $\alpha-\mathrm{Al}_{2} \mathrm{O}_{3}, \quad \mathrm{cBN}$, and $\mathrm{ZrO}_{2}$, the same as initial compositions of the proportioning scheme, which demonstrates that there were no chemical reactions among $\alpha-\mathrm{Al}_{2} \mathrm{O}_{3}, \mathrm{cBN}$, and $\mathrm{ZrO}_{2}$ during sintering process.

As to Sample $\mathrm{S} 1, \beta$-SiAlON $\left(\mathrm{Si}_{4} \mathrm{Al}_{2} \mathrm{O}_{2} \mathrm{~N}_{6}\right)$ and $\mathrm{O}^{\prime}$-SiAlON $\left(\mathrm{Si}_{1.8} \mathrm{Al}_{0.2} \mathrm{O}_{1.2} \mathrm{~N}_{1.8}\right)$ phases were produced from the reaction among $\mathrm{Si}_{3} \mathrm{~N}_{4}, \mathrm{Al}_{2} \mathrm{O}_{3}$, and $\mathrm{AlN}$. The $\mathrm{Si}-\mathrm{N}$ bonds of $\mathrm{Si}_{3} \mathrm{~N}_{4}$ were constantly replaced by Al-O bonds of $\mathrm{Al}_{2} \mathrm{O}_{3}$ to construct $\beta$-SiAlON ceramic as a result of similar bond length between $\mathrm{Al}-\mathrm{O}(1.75 \AA)$ and Si-N (1.74 $\AA$ ) bonds to keep charge balance [26]. The chemical equation could be expressed as follows:

$4 \mathrm{Si}_{3} \mathrm{~N}_{4}+2 \mathrm{Al}_{2} \mathrm{O}_{3}+2 \mathrm{AlN}=3 \mathrm{Si}_{4} \mathrm{Al}_{2} \mathrm{O}_{2} \mathrm{~N}_{6}(\beta-\mathrm{SiAlON})$

SiAlON ceramics have superior sinterability, excellent mechanical properties, and good high temperature performance including high temperature strength, oxidation resistance, and thermal shock resistance, thereby having widely application prospects as structural components and cutting tools [27,28]. Sample S3 mainly produced new reaction products of $\mathrm{TiB}_{2}, \mathrm{AlB}_{2}$, TiN, AlN, as well as minor amounts of $\mathrm{hBN}$ when sintered at $1500{ }^{\circ} \mathrm{C}$. The corresponding chemical equations could be expressed as follows [18]:

$$
\begin{aligned}
& 3 \mathrm{Al}+2 \mathrm{BN}=2 \mathrm{AlN}+\mathrm{AlB}_{2} \\
& 3 \mathrm{Ti}+2 \mathrm{BN}=2 \mathrm{TiN}+\mathrm{TiB}_{2}
\end{aligned}
$$

The metal phases $\mathrm{Al}$ and $\mathrm{Ti}$ can promote density of composites during sintering process by filling the clearance of $\mathrm{cBN}$ particles, activating the surface of $\mathrm{cBN}$, and reacting with $\mathrm{cBN}$ [18]. Meanwhile, the chemical reactions produced $\mathrm{TiN}, \mathrm{AlN}$, and $\mathrm{TiB}_{2}$ phases with high strength, hardness, and chemical stability, which were conducive to improving the mechanical properties of composites. Nevertheless, the phase transformation from $\mathrm{cBN}$ to $\mathrm{hBN}$ could result in degradation of mechanical properties and density of the composites on account of weak bond between interlayers of hBN similar to graphite. Although the same and even higher sintered temperature was adopted in Samples S1 and S2, there was no hBN phase detected, indicating that these binder systems contribute to the inhibition of the phase transition.

The morphologies of three kinds of PcBN composites are shown in Fig. 3. Different phases can be distinguished easily due to their distinct atomic number from BSE images (Figs. 3(a)-3(c)). The larger black contrasts (zones 1, 3, and 6 in Fig. 3) dispersed in PcBN composites
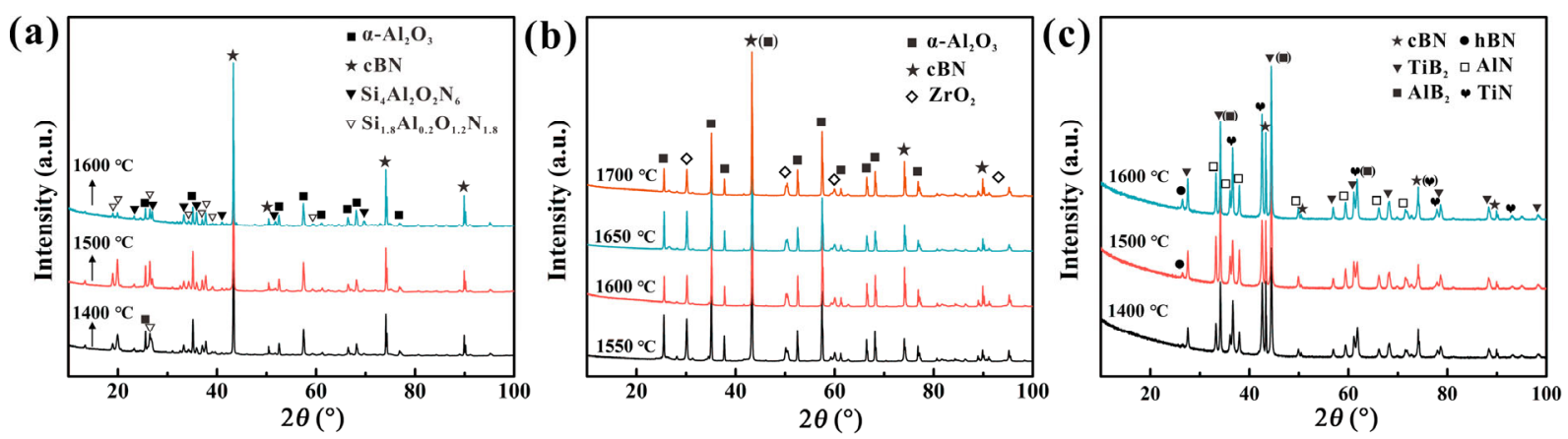

Fig. 2 XRD spectra of the PcBN composites sintered at different temperatures: (a) Sample S1, (b) Sample S2, and (c) Sample S3. 
were mainly composed of cBN particles with large amounts of $\mathrm{B}$ and $\mathrm{N}$ elements, as shown in corresponding element weight percent. And the particle size of $\mathrm{cBN}$ was $5-10 \mu \mathrm{m}$ resulted from raw microsized powders. Some element weight percents in other zones were also given in Fig. 3. For Sample S1, the gray area (zone 2) was mainly $\alpha-\mathrm{Al}_{2} \mathrm{O}_{3}$ and SiAlON phases (Fig. 3(a)). The gray and white areas (zones 4 and 5) were mainly formed by $\alpha-\mathrm{Al}_{2} \mathrm{O}_{3}, \mathrm{ZrO}_{2}(3 \mathrm{Y})$, and a bit of $\mathrm{cBN}$ (Fig. 3(b)). The gray (zone 8) and white (zone 7) areas in Sample S3 were mainly composed of TiN, AlN, $\mathrm{TiB}_{2}, \mathrm{AlB}_{2}$, and a small quantity of BN (Fig. 3(c)). There are no obvious interfacial defects like cracks, holes, or fragments in the composites. And the polygonal cBN particles surrounded by binder phases relatively uniformly distributed in composites to construct a continuous net structure in Samples S1 and S2. Nevertheless, Sample S3 exhibited obvious agglomeration and maldistribution of $\mathrm{cBN}$ particles compared with that of Samples S1 and S2, and it can be ascribed to the difference of plasticity and fluidity between ceramic and metal during sintering.
It is favorable to improve sintering temperature for promoting the compactness of PcBN composites (Fig. 4). The apparent porosity of Samples S1 and S2 could reduce to $0.44 \%$ and $0.74 \%$ at the sintered temperature of 1600 and $1700{ }^{\circ} \mathrm{C}$, respectively, while that of Sample S3 just decreased to $7.68 \%$ at sintered temperature of $1600{ }^{\circ} \mathrm{C}$. Meanwhile, the maximum bulk densities of three samples were obtained at 1600 $1700{ }^{\circ} \mathrm{C}$, which were $3.34,3.60$, and $3.49 \mathrm{~g} / \mathrm{cm}^{3}$. Although Sample S3 presented the highest porosity, it simultaneously possessed high bulk density because of the high density of metal binder system. Low apparent porosity could produce a considerable promotion on carrying capacity of materials, thereby directly improving mechanical properties.

\section{2 Influence of binder systems and formulas on mechanical properties}

The mechanical performance is a crucial parameter to evaluate carrying capacity and damage resistance of ceramic materials. To elucidate the influences of binder
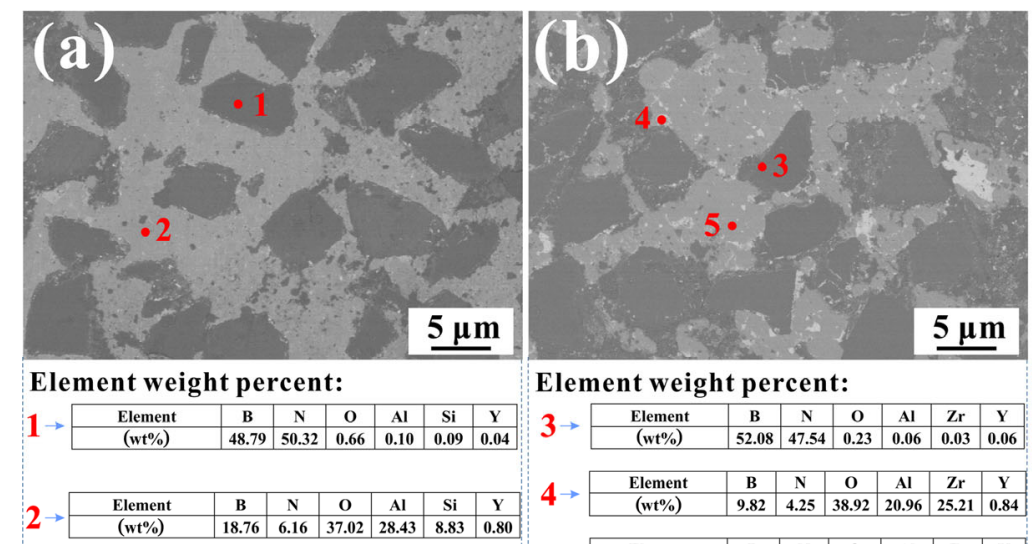

Element weight percent:

$\mathbf{3} \rightarrow$\begin{tabular}{|c|c|c|c|c|c|c|}
\hline Element & B & N & O & Al & Zr & Y \\
\hline$(w 1 \%)$ & 52.08 & 47.54 & 0.23 & 0.06 & 0.03 & 0.06 \\
\hline
\end{tabular}

4 $\rightarrow$\begin{tabular}{|c|c|c|c|c|c|c|}
\hline Element & B & N & O & Al & Zr & Y \\
\hline (wt\%) & 9.82 & 4.25 & 38.92 & 20.96 & 25.21 & 0.84 \\
\hline
\end{tabular}

$\mathbf{5} \rightarrow$\begin{tabular}{|c|c|c|c|c|c|c|}
\hline Element & $\mathrm{B}$ & $\mathrm{N}$ & $\mathbf{O}$ & $\mathrm{Al}$ & $\mathrm{Zr}$ & $\mathrm{Y}$ \\
\hline (wt\%) & $\mathbf{3 2 . 0 9}$ & $\mathbf{8 . 0 5}$ & 31.62 & 27.95 & $\mathbf{0 . 2 9}$ & $\mathbf{0}$ \\
\hline
\end{tabular}

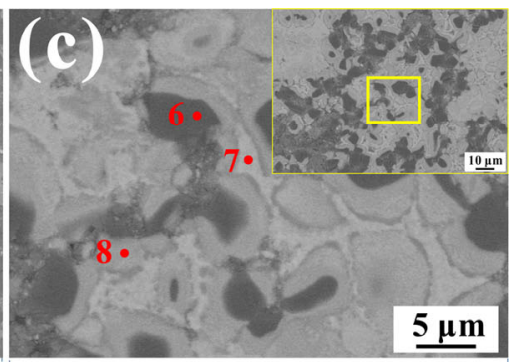

Element weight percent:

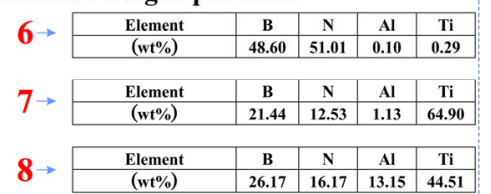

Fig. 3 BSE morphologies and element weight percents with different areas of polished surfaces of (a) Sample S1 sintered at $1600{ }^{\circ} \mathrm{C}$, (b) Sample S2 sintered at $1700{ }^{\circ} \mathrm{C}$, and (c) Sample S3 sintered at $1600{ }^{\circ} \mathrm{C}$.
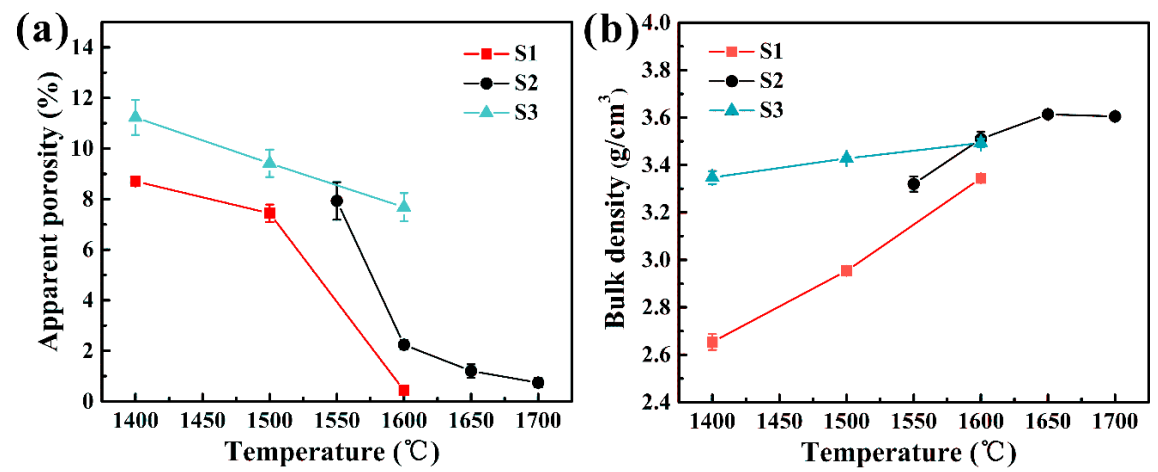

Fig. 4 (a) Apparent porosity and (b) bulk density of three kinds of PcBN composites sintered at different temperatures. 
formulas and sintered temperatures on the mechanical properties of PcBN composites, HV, flexural strength $(\sigma)$, and fracture toughness $\left(K_{\mathrm{IC}}\right)$ of three kinds of PcBN composites sintered at different temperatures were measured, and the results are given in Figs. 5 and 6. From Figs. 5 and 6, it can be seen that the mechanical properties were generally improved with the increase of sintered temperature in general. At the same time, the binder systems and formulas also have significant influence on mechanical performances. The hardness of three kinds of PcBN composites showed contrary tendency to their apparent porosity, indicating that the variation of hardness related to their binder phases and densification. The hardness of Samples S1, S2, and S3 reached a maximum value of $15.59 \pm 0.54,14.83 \pm 0.82$, and $14.14 \pm 0.65 \mathrm{GPa}$, respectively.

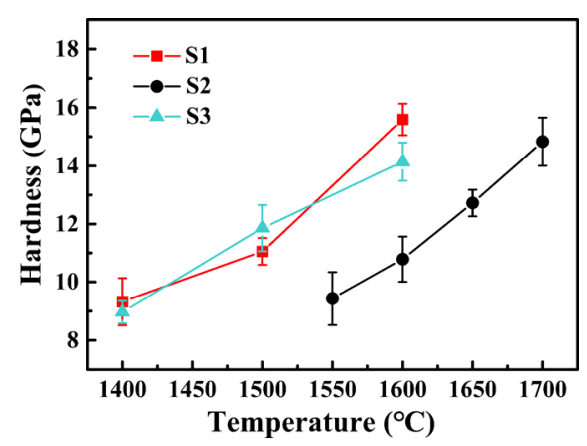

Fig. 5 Vickers hardness of the PcBN composites sintered at different temperatures.
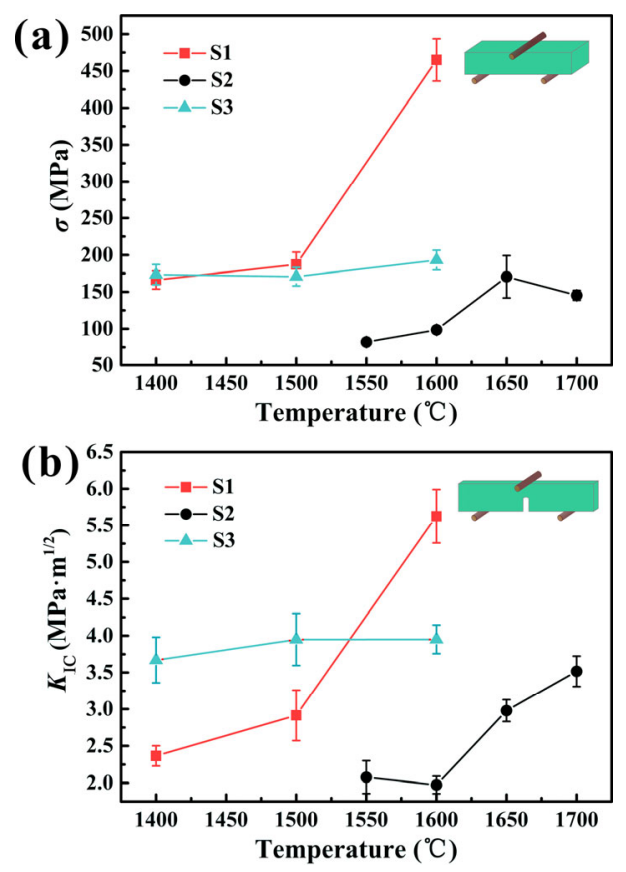

Fig. 6 (a) Flexural strength and (b) fracture toughness of the PcBN composites sintered at different temperatures.
The flexural strength and fracture toughness of the PcBN composites presented a great difference. Sample S1 exhibited a significant improvement and possessed a highest flexural strength and fracture toughness with the values of $465 \pm 29 \mathrm{MPa}$ and $5.62 \pm 0.37 \mathrm{MPa} \cdot \mathrm{m}^{1 / 2}$, respectively, when the sintering temperature rose to $1600{ }^{\circ} \mathrm{C}$. Nevertheless, there was no significant improvement of flexural strength and fracture toughness of Sample S3, with relatively high initial value and low final value as the sintering temperatures increased from 1400 to $1600{ }^{\circ} \mathrm{C}$. Compared with Sample $\mathrm{S} 1$, Sample S2 showed relative inferior carrying capacity and fracture resistance property with a slight improvement. Its flexural strength and fracture toughness just reach $145 \pm 7 \mathrm{MPa}$ and $3.52 \pm 0.21 \mathrm{MPa} \cdot \mathrm{m}^{1 / 2}$, respectively, when the sintering temperature increases up to $1700{ }^{\circ} \mathrm{C}$. The mechanical properties of PcBN composites can be attributed to the relative density, binding force between different phases, as well as the fracture mechanisms of samples, which will be discussed below.

The microstructures of fracture surfaces of the PcBN composites after fracture testing are shown in Fig. 7. The rough and uneven fractural morphologies could be observed directly. The features of $\mathrm{cBN}$ particle pullout and tear as well as brittle fracture of SiAlON phase were presented in the fracture surface of Sample S1 (Fig. 7(a)), demonstrating that the fracture pattern similar to transgranular and intergranular fractures simultaneously existed in the PcBN composites during fracture process. Meanwhile, there are no obvious cracks or pores between $\mathrm{cBN}$ particles and SiAlON phases, indicating good interface bond, thereby improving the strength of the composites. As for Sample S2, cBN particles pulled out with obvious particles and deep pits, indicating that the cracks could easily propagate from the weak bonding strength between cBN particles and $\mathrm{Al}_{2} \mathrm{O}_{3}$ phase (Fig. 7(b)). The weak bonding strength may be mainly due to the conspicuous difference of thermal expansion coefficient between cBN $\left((1.2-3.4) \times 10^{-6} \mathrm{~K}^{-1}\right)$ and $\mathrm{Al}_{2} \mathrm{O}_{3}(7.2 \times$ $\left.10^{-6} \mathrm{~K}^{-1}\right)$ phases, which resulted in high residual stress and thermal stress concentration at their interface [11]. Moreover, the $\mathrm{Al}_{2} \mathrm{O}_{3}$ phase also presented typical transgranular fracture characteristics with clear grain boundaries. Thus, Sample S2 presented poor flexural strength and fracture toughness. Additionally, some pores can be observed in the fracture surface of Sample S3 (Fig. 7(c)), which was consistent with its high porosity and was the main adverse factor for the mechanical 

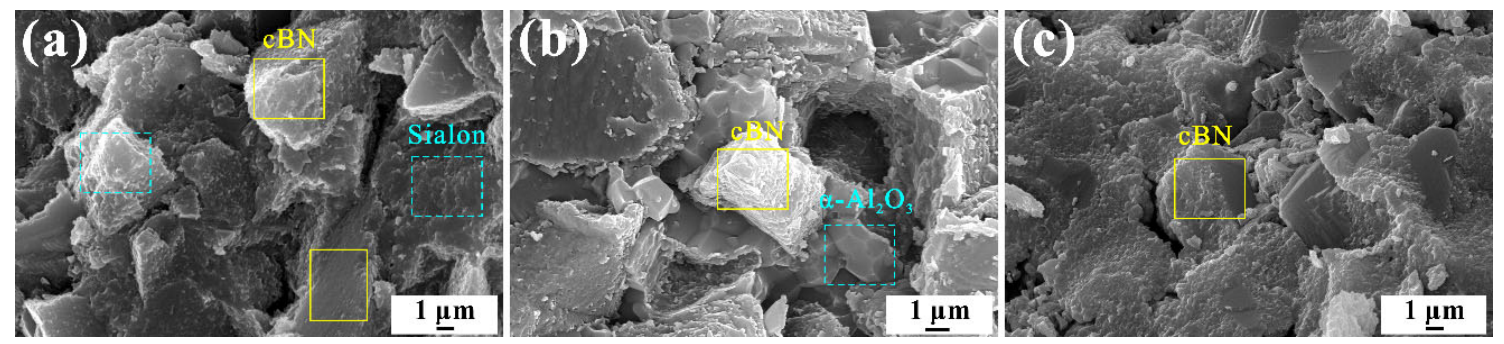

Fig. 7 SEM morphologies of fracture surfaces of the PcBN composites: (a) sample S1 sintered at $1600{ }^{\circ} \mathrm{C}$, (b) Sample S2 sintered at $1700{ }^{\circ} \mathrm{C}$, and (c) Sample S3 sintered at $1600{ }^{\circ} \mathrm{C}$.

properties. Moreover, the phase transformation of $\mathrm{cBN}$ would also weaken the bonding strength between $\mathrm{cBN}$ particles and binder phases by generating new weak phase of hBN. Hence, the binder phases played the key roles for maintaining the mechanical properties of the PcBN composites. The intergranular fracture will assume much more fracture energy compared with transgranular fracture as a result of laniating particles with strong bond, and previous research illustrated the fracture mode of a mixed fracture of intergranular and transgranular of ceramic composites resulted from a balance between the grain boundary "strengthening" and grain "weakening" exhibiting the optimal strength [29].

To further confirm the above descriptions, the crack propagation paths of the $\mathrm{PcBN}$ composites were further observed and the results are shown in Fig. 8, which can reflect crack propagating along phase interfaces or across cBN particles, thereby indicating the bonding strength between $\mathrm{cBN}$ particles and binder phases. Obviously, both cracks propagating through cBN particles and SiAlON phase existed in Sample S1 except for along with their interfaces (Figs. 8(a) and 8(d)).
It was these fracture behaviors that could efficiently improve the carrying capacity as a result of cracks through cBN particles and deflection at the interfaces. As for Sample S2, however, cracks almost completely propagated along with the interfaces between cBN particles and $\mathrm{Al}_{2} \mathrm{O}_{3}$ phase, illustrating that it was easy for cracks to propagate rapidly accompanied by the drawing of cBN particles and small quantities of microcracks. The inferior mechanical properties were attributed to the poor bonding strength that could reduce its carrying capacity. Furthermore, cracks in Sample S3 mainly propagated through the binder phases with some cBN particles pulling out other than through $\mathrm{cBN}$ particles, indicating the bonding strength between $\mathrm{cBN}$ particles and binder phases together with the performance of binder phases limiting the mechanical properties.

Therefore, the binder systems and formulas are critical for the mechanical properties of PcBN composites by means of influencing fracture model and crack behaviors, which were decided by performance of binder phases and the bonding strength between $\mathrm{cBN}$ particles and binder phases.
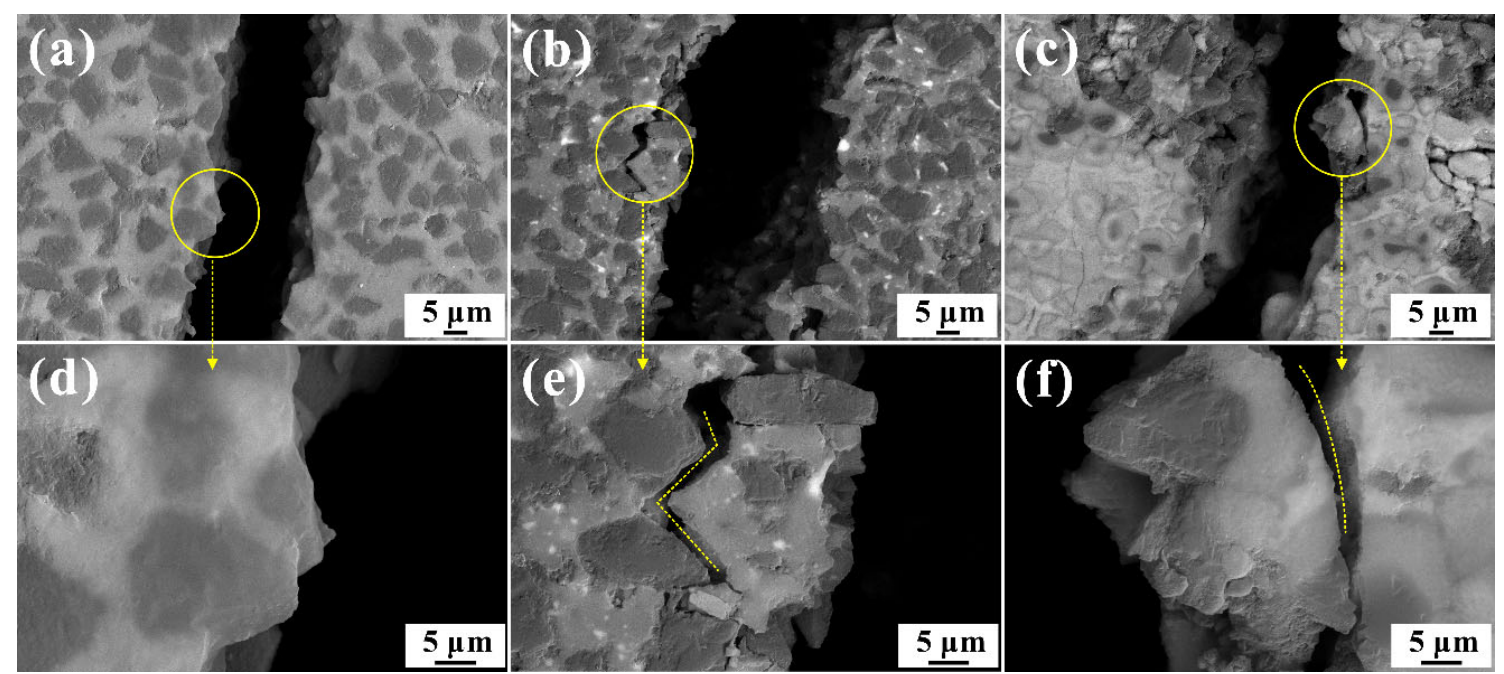

Fig. 8 SEM morphologies of crack propagation path after mechanical tests: (a, d) Sample S1 sintered at $1600{ }^{\circ} \mathrm{C}$, (b, e) Sample S2 sintered at $1700{ }^{\circ} \mathrm{C}$, and (c, f) Sample S3 sintered at $1600{ }^{\circ} \mathrm{C}$. 


\section{3 Mechanical properties of the PcBN composite at elevated temperatures}

Considering the local temperature rise of the composite as mentioned in Section 1, its high temperature mechanical properties are even more important for determining the actual service performance and life. The Sample S1 with superior mechanical properties at RT was selected to evaluate its high temperature mechanical performances at 400,600 , and $800{ }^{\circ} \mathrm{C}$. The results are shown in Fig. 9. With the test temperature increasing, the fracture toughness showed a slight downward trend, demonstrating that the environment temperature had a certain effect. Even at $800{ }^{\circ} \mathrm{C}$, however, the fracture toughness can maintain at a relatively high value $\left(5.13 \pm 0.40 \mathrm{MPa} \cdot \mathrm{m}^{1 / 2}\right)$, which was only $8.7 \%$ less than that at RT. There was no obvious attenuation of the flexural strength but a slight increase and the values were always not less than $450 \mathrm{MPa}$ with elevating test temperatures. It can reach $545 \pm 37$, and $467 \pm 18 \mathrm{MPa}$ at 600 and $800{ }^{\circ} \mathrm{C}$, respectively. The reduction of fracture toughness was probably related to the softening of SiAlON phases at high temperatures, insufficient thermal resistance, and poor grain boundary bond, which led to the degradation of its mechanical properties at high temperatures [30-32]. On the whole, the composite can still maintain considerable mechanical properties at high temperatures without obvious reduction, illustrating that the material possessed excellent carrying capacity from RT to $800{ }^{\circ} \mathrm{C}$.

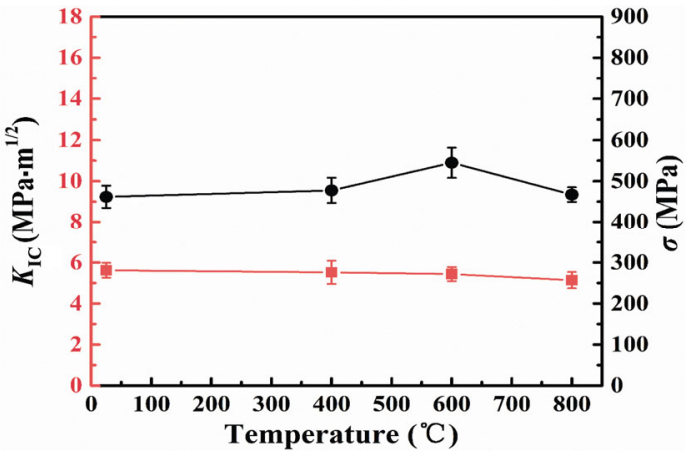

Fig. 9 High temperature mechanical properties of Sample S1 at elevated temperatures.

The morphologies of fracture surfaces and crack propagation path after the mechanical property tests at elevated temperatures are shown in Figs. 10 and 11, respectively. Similar to the morphologies tested at RT, the characteristics of cBN particle pullout and SiAlON phase brittle failure could be observed from Figs. 10 and 11. Crack deflection, unit broken, and $\mathrm{cBN}$ particle pullout and tear could also be observed from crack propagation pattern (Fig. 11). When test temperature raised to $800{ }^{\circ} \mathrm{C}$, the crack propagation path became straighter because the crack propagated predominately through SiAlON phase with few cBN particle pullout. All of above implied that the binder system has good performances and interaction with $\mathrm{cBN}$ particles from RT to $800{ }^{\circ} \mathrm{C}$. Therefore, the $\mathrm{PcBN}$ composite adopting Sample $\mathrm{S} 1$ as binder system could maintain considerable high strength, toughness, and stability to resist damage from RT to $800{ }^{\circ} \mathrm{C}$.

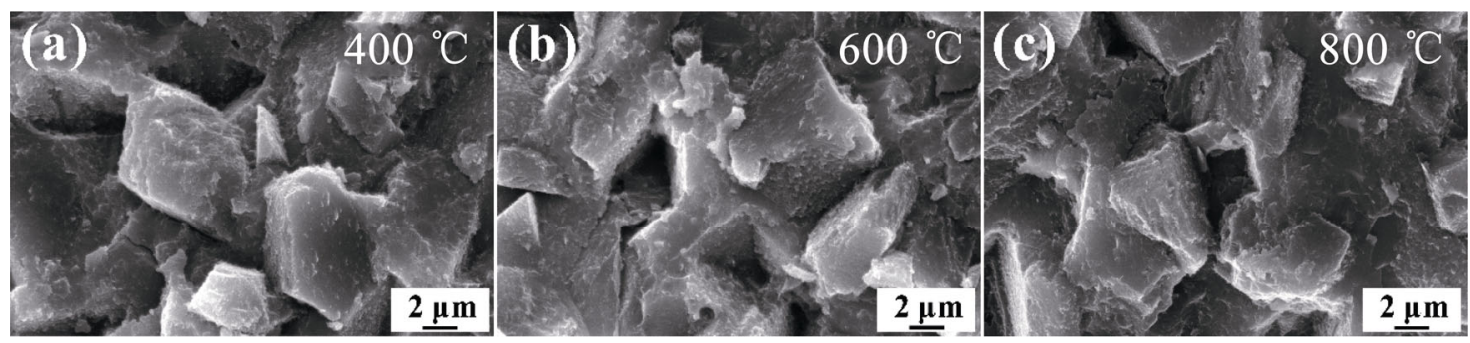

Fig. 10 SEM morphologies of fracture surfaces after the mechanical property tests at elevated temperatures.
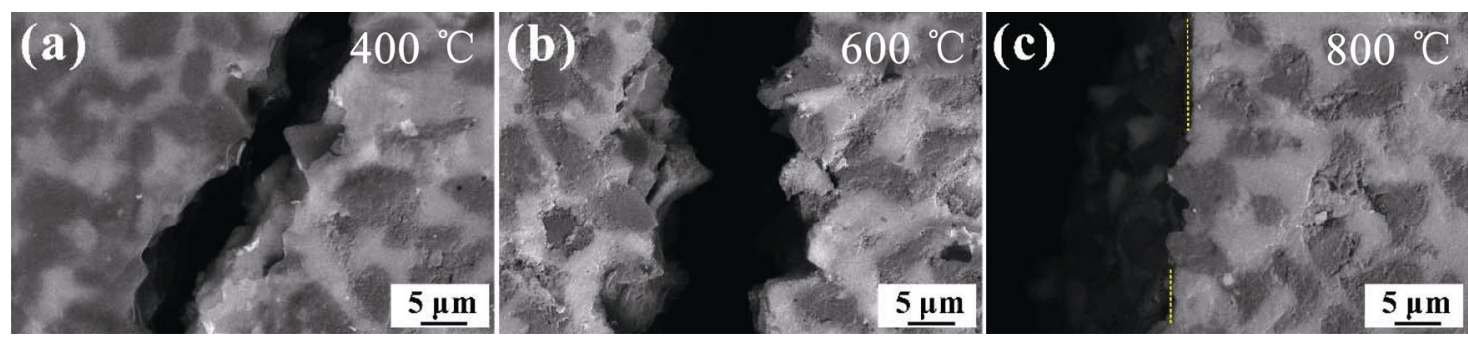

Fig. 11 SEM morphologies of crack propagation path after the mechanical property tests at elevated temperatures. 


\section{Conclusions}

In this study, the PcBN composites with different systems and formulas of binders were fabricated at $1400-1700{ }^{\circ} \mathrm{C}$ by SPS. The sintering characteristics, compositions, microstructures, and mechanical properties of composites were investigated. The following conclusions can be drawn:

1) The proportioning schemes of PcBN composites have a great influence on the sintering characteristics. The binder systems of Samples S1 and S2 can restrain the phase transition of $\mathrm{cBN}$ and promote the compactness of the composites, and the apparent porosity can reduce to less than $0.8 \%$.

2) The mechanical properties of the PcBN composites are determined by binder systems and formulas. The good mechanical performances and appropriate coefficient of thermal expansion of binders influence the fracture characteristics. The flexural strength and fracture toughness of the PcBN composite with SiAlON phase as binder can reach $465 \pm 29 \mathrm{MPa}$ and $5.62 \pm 0.37 \mathrm{MPa} \cdot \mathrm{m}^{1 / 2}$, respectively.

3) The PcBN composite with SiAlON phase as binder can maintain considerable mechanical performance from RT to $800{ }^{\circ} \mathrm{C}$. The flexural strength and fracture toughness can reach $467 \pm 18 \mathrm{MPa}$ and $5.13 \pm 0.40$ $\mathrm{MPa} \cdot \mathrm{m}^{1 / 2}$, respectively, at $800{ }^{\circ} \mathrm{C}$, attributing to the good performance and interaction of the binder phase with $\mathrm{cBN}$ particles.

\section{Acknowledgements}

This work was supported by the National Natural Science Foundation of China (No. 51775534), the West Light Foundation of the Chinese Academy of Sciences (2019), and the LICP Cooperation Foundation for Young Scholars (No. HZJJ21-07).

\section{References}

[1] Denkena B, Grove T, Müller-Cramm D, et al. Influence of the cutting direction angle on the tool wear behavior in face plunge grinding of PcBN. Wear 2020, 454-455: 203325.

[2] McKie A, Winzer J, Sigalas I, et al. Mechanical properties of cBN-Al composite materials. Ceram Int 2011, 37: 1-8.

[3] Mo P, Chen C, Jia G, et al. Effect of tungsten content on microstructure and mechanical properties of PCBN synthesized in cBN-Ti-Al-W system. Int $J$ Refract Met Hard Mat 2020, 87: 105138.
[4] Klimczyk P, Cura ME, Vlaicu AM, et al. $\mathrm{Al}_{2} \mathrm{O}_{3}-\mathrm{cBN}$ composites sintered by SPS and HPHT methods. $J$ Eur Ceram Soc 2016, 36: 1783-1789.

[5] Ji H, Li Z, Sun K, et al. Effect of $\mathrm{Y}_{2} \mathrm{O}_{3}$ additive on properties of cBN composites with $\mathrm{Si}_{3} \mathrm{~N}_{4}-\mathrm{Al}_{2} \mathrm{O}_{3}-\mathrm{Al}$ as binder by high temperature and high pressure sintering. Ceram Int 2019, 45: 20478-20483.

[6] Rong XZ, Tsurumi T, Fukunaga O, et al. High-pressure sintering of cBN-TiN-Al composite for cutting tool application. Diamond Relat Mater 2002, 11: 280-286.

[7] Taniguchi T, Akaishi M, Yamaoka S. Sintering of cubic boron nitride without additives at $7.7 \mathrm{GPa}$ and above $2000{ }^{\circ} \mathrm{C}$. J Mater Res 1999, 14: 162-169.

[8] Mo P, Chen C, Chen J, et al. Effect of sintering temperature on synthesis of PCBN in cBN-Ti-Al-W system. Diam Relat Mater 2020, 103: 107714.

[9] Angseryd J, Elfwing M, Olsson E, et al. Detailed microstructure of a cBN based cutting tool material. Int $J$ Refract Met Hard Mater 2009, 27: 249-255.

[10] Liu Y, Sun A, Zhong S, et al. Effect of Al-Ti content on mechanical properties of in-situ synthesized PcBN composites. Diam Relat Mat 2020, 109: 108068.

[11] Yu R, Melnichuk I, Garashchenko V, et al. Influence of cBN content, $\mathrm{Al}_{2} \mathrm{O}_{3}$ and $\mathrm{Si}_{3} \mathrm{~N}_{4}$ additives and their morphology on microstructure, properties, and wear of $\mathrm{PCBN}$ with $\mathrm{NbN}$ binder. Ceram Int 2020, 46: 22230- 22238.

[12] Klimczyk P, Wyżga P, Cyboroń J, et al. Phase stability and mechanical properties of $\mathrm{Al}_{2} \mathrm{O}_{3}-\mathrm{cBN}$ composites prepared via spark plasma sintering. Diam Relat Mater 2020, 104: 107762.

[13] Rampai T, Lang CI, Sigalas I. Investigation of MAX phase/c-BN composites. Ceram Int 2013, 39: 4739-4748.

[14] Zhang Z, Duan XM, Qiu BF, et al. Preparation and anisotropic properties of textured structural ceramics: A review. J Adv Ceram 2019, 8: 289-332.

[15] Hotta M, Goto T. Effect of time on microstructure and hardness of $\beta$-SiAlON-cubic boron nitride composites during spark plasma sintering. Ceram Int 2011, 37: 521-524.

[16] Dai JW, Mu RD, Wang X, et al. Effects of $\mathrm{ZrO}_{2}$ doping on mechanical and thermo-physical properties of $\mathrm{La}_{2} \mathrm{Ce}_{2} \mathrm{O}_{7}$ ceramics. Equip Environ Eng 2019, 16: 21-26. (in Chinese)

[17] Wang X, Ma Z, Sun X, et al. Effects of $\mathrm{ZrO}_{2}$ and $\mathrm{Y}_{2} \mathrm{O}_{3}$ on physical and mechanical properties of ceramic bond and ceramic CBN composites. Int J Refract Met Hard Mater 2018, 75: 18-24.

[18] Yuan Y, Cheng X, Chang R, et al. Reactive sintering cBN-Ti-Al composites by spark plasma sintering. Diam Relat Mater 2016, 69: 138-143.

[19] Permin DA, Boldin MS, Belyaev AV, et al. IR-transparent $\mathrm{MgO}-\mathrm{Gd}_{2} \mathrm{O}_{3}$ composite ceramics produced by selfpropagating high-temperature synthesis and spark plasma sintering. J Adv Ceram 2021, 10: 237-246.

[20] Ahmed BA, Laoui T, Hakeem AS. Development of calcium 
stabilized nitrogen rich $\alpha$-SiAlON ceramics along the $\mathrm{Si}_{3} \mathrm{~N}_{4}: 1 / 2 \mathrm{Ca}_{3} \mathrm{~N}_{2}$ :3AlN line using spark plasma sintering. $J$ Adv Ceram 2020, 9: 606-616.

[21] Garrett JC, Sigalas I, Herrmann M, et al. cBN reinforced Y- $\alpha$-SiAlON composites. J Eur Ceram Soc 2013, 33: 2191-2198.

[22] Ren XJ, Yang QX, James RD, et al. Cutting temperatures in hard turning chromium hardfacings with PCBN tooling. $J$ Mater Process Technol 2004, 147: 38-44.

[23] Vel L, Demazeau G, Etourneau J. Cubic boron nitride: Synthesis, physicochemical properties and applications. Mater Sci Eng: B 1991, 10: 149-164.

[24] Harris TK, Brookes EJ, Taylor CJ. The effect of temperature on the hardness of polycrystalline cubic boron nitride cutting tool materials. Int J Refract Met Hard Mater 2004, 22: 105-110.

[25] Dou YW, Kou ZL, Qi L, et al. Turning hardened bearing steel with PcBN tool. Daimond \& Abrasives Eng 2010, 30: 54-57. (in Chinese)

[26] Gan L, Mao ZY, Zhang YQ, et al. Effect of composition variation on phases and photoluminescence properties of $\beta$-SiAlON:Ce ${ }^{3+}$ phosphor. Ceram Int 2013, 39: 4633-4637.

[27] Acikbas NC, Demir O. The effect of cation type, intergranular phase amount and cation mole ratios on $z$ value and intergranular phase crystallization of SiAlON ceramics. Ceram Int 2013, 39: 3249-3259.

[28] Barick P, Jana DC, Saha BP. Load-dependent indentation behavior of $\beta$-SiAlON and $\alpha$-silicon carbide. J Adv Ceram 2013, 2: 185-192.
[29] Sun X, Li JG, Guo S, et al. Intragranular particle residual stress strengthening of $\mathrm{Al}_{2} \mathrm{O}_{3}-\mathrm{SiC}$ nanocomposites. $\mathrm{J} \mathrm{Am}$ Ceram Soc 2005, 88: 1536-1543.

[30] Sun Q, Yang J, Yu Y, et al. The novel SiAlON-Sn composite with high toughness and wear resistance prepared at a lower-temperature. Tribol Int 2020, 147: 106239.

[31] Sun QC, Wang ZX, Yang J, et al. High-performance TiN reinforced SiAlON matrix composites: A good combination of excellent toughness and tribological properties at a wide temperature range. Ceram Int 2018, 44: 17258-17265.

[32] Klemm H, Herrmann M, Reich T, et al. High-temperature properties of mixed $\alpha^{\prime} / \beta^{\prime}$-SiAlON materials. J Am Ceram Soc 2005, 81: 1141-1148.

Open Access This article is licensed under a Creative Commons Attribution 4.0 International License, which permits use, sharing, adaptation, distribution and reproduction in any medium or format, as long as you give appropriate credit to the original author(s) and the source, provide a link to the Creative Commons licence, and indicate if changes were made.

The images or other third party material in this article are included in the article's Creative Commons licence, unless indicated otherwise in a credit line to the material. If material is not included in the article's Creative Commons licence and your intended use is not permitted by statutory regulation or exceeds the permitted use, you will need to obtain permission directly from the copyright holder.

To view a copy of this licence, visit http://creativecommons. org/licenses/by/4.0/. 